doi: $10.15407 /$ ujpe62.09.0818

M.I. ISLAM, ${ }^{1}$ M. KHATUN,${ }^{1}$ K. AHMED,${ }^{1,2}$ S. ASADUZZAMAN,${ }^{1,2,3}$ B.K. PAUL,${ }^{1,2}$ M.S. ISLAM, ${ }^{1,2}$ S. CHOWDHURY, ${ }^{1,2}$ S. SEN ${ }^{1,2}$ M.B.A. MIAH, ${ }^{1,2}$ A.N. BAHAR ${ }^{1,2}$

${ }^{1}$ Department of Information and Communication Technology Mawlana Bhashani Science and Technology University (Santosh, Tangail-1902, Bangladesh; e-mail: kawsar.ict@mbstu.ac.bd)

${ }^{2}$ Group of Bio-photomatix (Bangladesh; e-mail: k.ahmed.bd@ieee.org)

${ }^{3}$ Department of Software Engineering, Daffodil International University (Savar, Dhaka-120\%, Bangladesh; e-mail: sayed.swe@diu.edu.bd)

\title{
DESIGN AND ANALYSIS
} OF SINGLE-MODE PCF IN OPTICAL COMMUNICATION COVERING E TO L BANDS

PACS 42.81.-i, 78.67.Pt, 84.40.Ua WITH ULTRA-HIGH NEGATIVE DISPERSION

\begin{abstract}
A single-mode square photonic crystal fiber (S-PCF) for the wide-band dispersion compensation at the wavelength interval 1340 to $1640 \mathrm{~nm}$ over the telecommunication windows is represented. In the numerical analysis of several guiding properties of the photonic crystal fiber (PCF), a finite-element method has been applied over the entire wavelength band. According to the investigation, the proposed $P C F$ is strongly single-mode, has an ultra-high negative dispersion coefficient of about -1732.10 ps/( $\mathrm{nm} \cdot \mathrm{km})$ at an operating wavelength of $1550 \mathrm{~nm}$, and is perfectly applicable to optical transmission systems. The single-mode behavior of the S-PCF is examined by applying the $V$ parameter. By the exquisite dispersion analysis, this fiber is more robust for obtaining the ultra-high negative dispersion, which gains more promiscuous as compared to the prior best results. For high-speed transmission systems, such fibers are effective as compensating the dispersion and maintaining a single polarization, as well as in fiber loop mirrors and many other applications like the four-wave mixing.
\end{abstract}

Keywords: ultra-high negative dispersion, dispersion-compensating S-PCF, single-mode fiber, optical communication.

\section{Introduction}

In recent years, the optical fiber is an extremely crucial factor in the information superhighway [1]. The invention of the fiber optics is the steadily remarkable technological breakthrough in telecom systems because of its larger attractive features [2]. The fiber in telecom systems permits the signal transmission over longer distances at broader bandwidths than other forms of communications. Moreover, these types of fibers are widely used for both telecom applications and in non-telecom systems. Their popularity is exponentially increased for remote sensing, medical imaging, machining, and welding applications because

(C) M.I. ISLAM, M. KHATUN, K. AHMED,

S. ASADUZZAMAN, B.K. PAUL, M.S. ISLAM,

S. CHOWDHURY, S. SEN, M.B.A. MIAH,

A.N. BAHAR, 2017 of the small size, lighter weight, higher bandwidth, longer repeater span, electromagnetic immunity, and many other challenging properties [3-5]. The waveguide is typically made from two glasses, which are a solid glass core with higher refractive index and the other solid glass with lower refractive index surrounding the core and making the homogeneous cladding. Although the present state-of-art of such fibers constitutes a far-flung usage in both telecom and non-telecom applications, there is something that these fibers simply cannot do. This difficulty of these fibers has led to another potential breakthrough in the fiber-optics technology, the invention of the photonic crystal fiber (PCF) which is also called the micro structured optical fiber (MOF) [6].

The PCFs or MOFs have contained a single material optical fiber, which consists of microscopic air holes in a silica background running down the en-

ISSN 2071-0194. Ukr. J. Phys. 2017. Vol. 62, No. 9 
tire length of the fiber that forms the silica-air microstructure and the periodic or aperiodic fashion lower refractive index cladding [7]. In general, PCFs can guide light by the two kinds of mechanisms: one involves an index-guiding PCF with the total internal reflection and another one does a photonic band gap fiber [4], where the periodically disseminated air holes in the cladding develop a photonic band gap, as well as a designed defect at the center forms the fiber core. PCFs can easily exceed conventional fibers in several scientific and technological fields of applications [8-16] for their superior and are easy to tailor their optical properties in the numerous potential challenging applications. In order to fully explore the advantages of the PCF technology over conventional fibers, those specific design requirements must be met efficiently. Some basic concepts of PCFs including the construction, light guiding mechanisms, types, fabrication techniques, and a number of unusual and previously unimaginable properties including, namely, endlessly single-mode operation [17], super-high nonlinearities [18], high birefringence [19], and ultra-low chromatic dispersion [19-21] had been presented. Although PCFs offer a great design flexibility, the design of PCFs with ultra-low negative dispersion, which is expected in almost all applications is remaining a big challenge for the researchers. This is due to the fact that, for most dispersion-managed applications, a higher non-linearity is also required in addition to dispersion characteristics.

The optical fiber dispersion plays a great role influenced by parameters of the silica-air microstructure, namely, the core diameter, air-hole diameter, as well as the position, air-hole pitch, and ellipticity. A number of rings also affect the dispersion parameter. A series of techniques signifying a modification of some parameters of fibers have been published in several papers so far [22-25]. In an optical fiber transmission system, a great controllability over the chromatic dispersion is a key quantity in various analyses and design issues for practical applications of PCFs. Therefore, our purpose was to design and to study a novel dispersion-controlling PCF and its optimum modal characteristics, which are presented in what follows. A comparison of modal properties of this fiber to some other PCFs in the references has also been given. Our main goal is to achieve the ultra-low dispersion over a broader wavelength interval for the applications of broadband dense wave- length division multiplexing (DWDM). This principle allows enhancing the negative dispersion in the dispersion-compensating fiber (DCF) which is extensively used to compensate the chromatic dispersion. The DCFs are the coupling between two spatially separated asymmetric concentric cores which maintain two leaky modes such as the inner and outer modes. However, some studies have concentrated on a few issues concerning thr ultra-high negative dispersion. As for broadband communication systems, we mention several attempts taken by distinct groups to achieve a high negative dispersion, as well as a desirable bandwidth for the dispersion compensation. Birks et al. [26] had first proposed the idea of using PCF for the dispersion compensation (DC) where the design suffered from its low compensation bandwidth. A similar approach was used in [27], whereby the proposed PCF was considered for a broadband DC with the lower dispersion coefficient of approximately $-475 \mathrm{ps} /(\mathrm{nm} \cdot \mathrm{km})$. In 2013 , a spiral microstructure optical fiber demonstrated the dispersion coefficient of $-327 \mathrm{ps} /(\mathrm{nm} \cdot \mathrm{km})$ with high birefringence of $1.79 \times 10^{-2}$, using a defected core in Ref. [28]. Again, an octagonal MOF structure in [29] exhibited the negative dispersion coefficient of $-588 \mathrm{ps} /(\mathrm{nm} \cdot \mathrm{km})$ with a high birefringence of $1.81 \times 10^{-2}$. In 2014, another DC-HyPCF design was proposed in [30], which offered a negative dispersion coefficient of $-1054.4 \mathrm{ps} /(\mathrm{nm} \cdot \mathrm{km})$ at $1550 \mathrm{~nm}$. In 2016, the MOF design was proposed by Amit Halder [31], which achieved an ultra-high negative dispersion coefficient of $-837.80 \mathrm{ps} /(\mathrm{nm} \cdot \mathrm{km})$ with a high nonlinearity of $53.45 \mathrm{~W}^{-1} \mathrm{~km}^{-1}$ over a wideband transmission system. Additionally, the high nonlinearity stays on one of the most promising applications of photonic crystal fibers.

With this context, we propose a novel design approach for achieving the ultra-high negative dispersion coefficient over broader telecommunication wavelengths. This approach can be improved by a great controllability over parameters for single-mode photonic crystal fibers (SMPCFs), while maintaining the uniformity of the PCF air-hole size. The effects of varying the diameters of air holes and varying the pitch have been studied to find the trends of the dispersion and the single-mode property and analyzed rigorously. The simulation effects show that the dispersion coefficient varies from -424.40 to $-3000.60 \mathrm{ps} /(\mathrm{nm} \cdot \mathrm{km})$ for wavelengths ranging from 


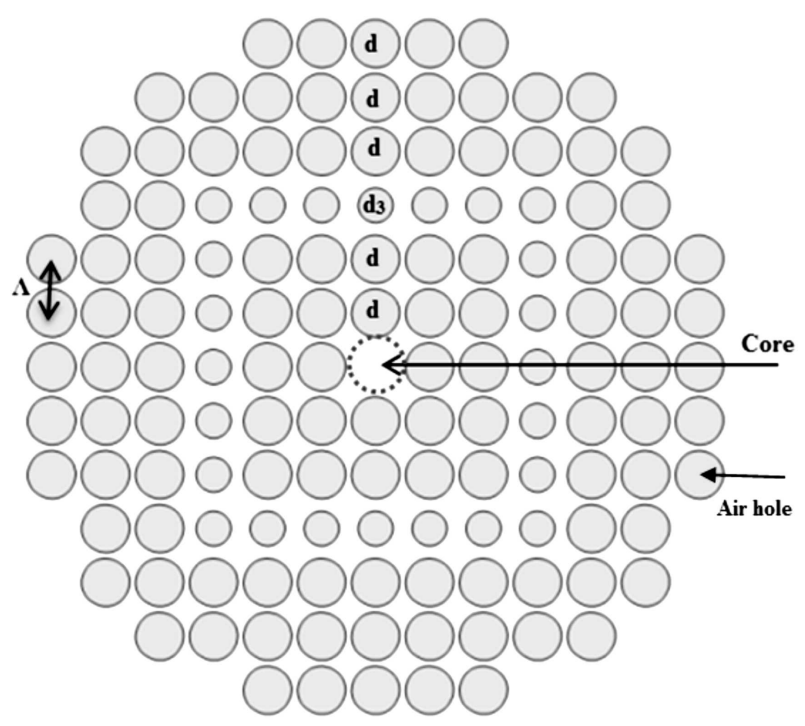

Fig. 1. Cross-sectional view of the proposed S-PCF

1340 to $1640 \mathrm{~nm}$ covering more than $\mathrm{E}+\mathrm{S}+\mathrm{C}+$ $+\mathrm{L}$ bands. Furthermore, the optimized parameters of the structure have been numerically investigated to analyze the results so that our proposed fiber for the control over the dispersion in PCFs works substantially and is more crucial in 40 Gbps high bit rate transmission systems.

\section{Geometrical Structure of the Proposed S-PCF}

Figure 1 depicts the cross-sectional view of the proposed square lattice PCF (S-PCF) with air hole distribution. Due to a lower refractive index and a higher air-filling ratio around the core region, it offers the strong confinement ability [32]. Adjacent air-holes in the entire cladding are transformed to circular air holes that will be effective to gain a large negative dispersion. It is determined that the dispersion property is affected by the size of air holes near the core [33]. In addition, by applying a traditional PCF topology, it is hard to engineer a large negative dispersion and to inspect the dispersion slope characteristics simultaneously. Consequently, it is essential to incorporate a design with a larger degree of independence regarding the entire geometrical structure parameters. Hence, the proposed structural parameters are defined as the pitch $\Lambda$ and air-hole diameters $d$ and $d_{3}$. The proposed PCF contains six air hole layers, in which the diameters of air holes of the $3^{\text {rd }}$ layer are denoted as $d_{3}$ and the rest diameters of air holes are same, which are denoted by $d$. In this case, in the squarelattice geometry of the proposed S-PCF, the hole-tohole distance both in horizontal and vertical directions $[34,35]$ is denoted as $\Lambda$. For the design flexibility, the air diameters are kept the same except for the third layer. To construct the inner core, the central air-holes are missed, which forces us to obtain the high negative dispersion. Due to the influence on dispersion properties, only a single material, usually silica, is used for the proposed PCF. The refractive index of silica has been evaluated through Sellmier's equation.

\section{Synopsis of the Numerical Method}

The FEM including a circular perfectly matched layer boundary condition is used to carry out the numerical simulation for investigating the guiding characteristics of the proposed structure for the dispersion compensation. By applying FEM, Maxwell's vectorial equation [36] is solved to approximate the value of modal effective refractive indices $n_{\text {eff }}$ in the best way. The modal effective indices $\left(n_{\text {eff }}\right)$ are obtained from Eq. (2). Moreover, the dispersion coefficient $D(\lambda)$, effective area $\left(A_{\text {eff }}\right)$, and effective $V$ parameter $\left(V_{\text {eff }}\right)$ can be determined, by using Eqs. (3)-(5). To investigate the modal characteristics of the proposed $\mathrm{S}-\mathrm{PCF}$, commercial full vector finite-element software (COMSOL 4.2) is used. The background of the proposed square-lattice fiber usually is taken to be silica, whose refractive index has been obtained through the following Sellmier's equation [8]:

$n(\lambda)=\sqrt{1+\frac{B_{1} \lambda^{2}}{\lambda^{2}-C_{1}}+\frac{B_{2} \lambda^{2}}{\lambda^{2}-C_{2}}+\frac{B_{3} \lambda^{2}}{\lambda^{2}-C_{3}}}$,

where $B_{1}, B_{2}, B_{3}, C_{1}, C_{2}, C_{3}$ are called Sellmier's coefficients.

The modal effective refractive index $\left(n_{\text {eff }}\right)$ is gained as a function of the wavelength and the material dispersion $\left(n_{m}(\lambda)\right)$. So that [37], we have

$n_{\mathrm{eff}}=\beta\left(\lambda, n_{m}(\lambda)\right) / k_{0}$,

where $\beta$ is the propagation constant, $k_{0}=2 \pi \lambda$ is the wave number of the free space, and $n_{m}(\lambda)$ can be estimated, by using the Sellemeier's formula.

The dispersion characteristics can be easily controlled by changing the shape, size, and pitch of air 
holes. The dispersion coefficient $D(\lambda)$ is calculated from the effective index of the fundamental mode $n_{\text {eff }}$ versus the wavelength, by using the equation [30]

$D(\lambda)=-\frac{\lambda}{c} \frac{d^{2} \operatorname{Re}\left[n_{\mathrm{eff}}\right]}{d \lambda^{2}} \mathrm{ps} /(\mathrm{nm} \cdot \mathrm{km})$,

where $\lambda$ is the wavelength, $c$ is the velocity of light in vacuum, $\operatorname{Re}\left[n_{\text {eff }}\right]$ is the real part of the effective indices obtained from simulations; $A_{\text {eff }}$ is the effective area which can be determined as [31]

$A_{\mathrm{eff}}=\frac{\left(\iint|E|^{2} d x d y\right)^{2}}{\iint|E|^{4} d x d y}$.

Now, we will consciously investigate the mode property of the proposed PCF. According to the effective $V$ parameter, it is seen that the single modeness of a fiber is changed inside the telecom band. $V_{\text {eff }}$ parameter for the PCF can be calculated by applying the equation [30]

$$
V_{\mathrm{eff}}=\frac{2 \pi \Lambda}{\lambda} \sqrt{n_{\mathrm{co}}^{2}-n_{\mathrm{cl}}^{2}} \text {. }
$$

This equation can be applied to verify the single-mode behavior of the proposed design, where $2 \pi \Lambda / \lambda$ denotes the wave number in the free space, $\Lambda$ is the pitch, and $n_{\mathrm{cl}}$ and $n_{\mathrm{co}}$ represent the effective index and refractive index of the cladding and the core, respectively.

\section{Results and Discussions}

Figure 2 exhibits the fundamental mode field profile of the proposed design at $1550 \mathrm{~nm}$ for both $x$ and $y$-polarization modes. From this figure, it is seen that the air-holes positions are evident, as well as the mode field is well absorbed in the core. The optical field is closely confined to the core region due to the high-index contrast at the center than in the cladding. The proposed PCF represents the increased design pliability in tailoring the dispersion and the nonlinear coefficient in a hasty manner as compared to the standard SMF.

To maintain the dispersion coefficient, there are three degrees of independence in the proposed structure denoted as $\Lambda, d$, and $d_{3}$. The dispersion coefficient of the proposed S-PCF as a function of the wavelength with the considered design parameters of $\Lambda=0.80 \mu \mathrm{m}, d=0.76 \mu \mathrm{m}$, and $d_{3}=0.55 \mu \mathrm{m}$ is

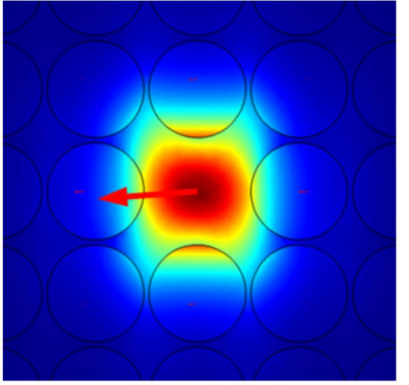

(a) x-polarization

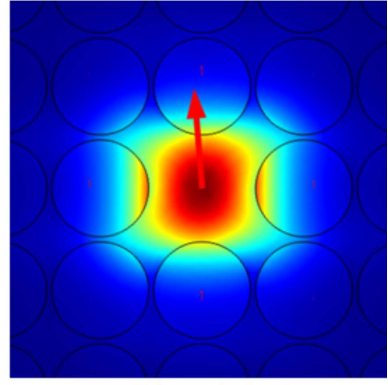

(b) y-polarization
Fig. 2. Field distributions of fundamental modes at the 1550$\mathrm{nm}$ wavelength for the $x$ - and $y$-polarizations

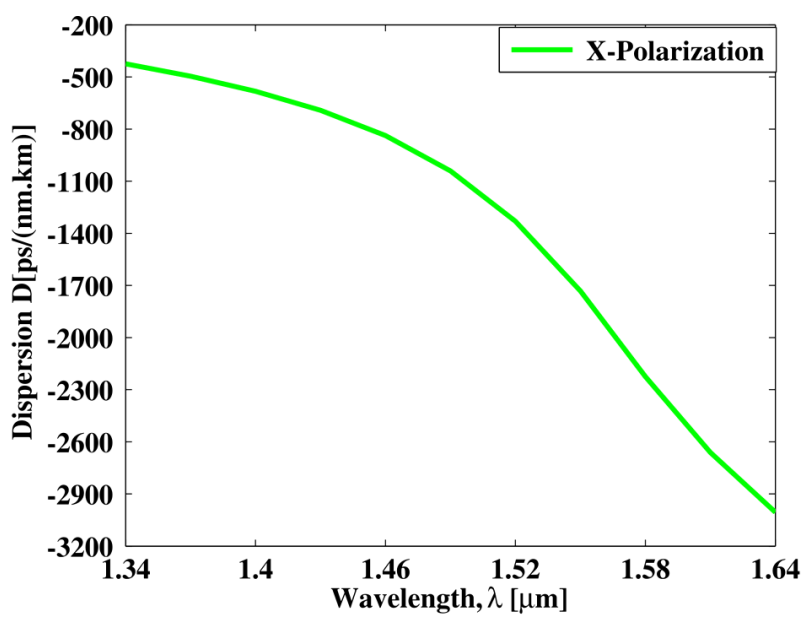

Fig. 3. Dispersion coefficient versus wavelength for the proposed S-PCF for the optimum design parameters: $\Lambda=$ $=0.80 \mu \mathrm{m} ; d=0.76 \mu \mathrm{m}$, and $d_{3}=0.55 \mu \mathrm{m}$

shown in Fig. 3 for $x$-polarization modes. From this figure, it can be observed that the dispersion values vary from -424.40 to $-3000.60 \mathrm{ps} /(\mathrm{nm} \cdot \mathrm{km})$ for the $x$-polarization around the spectral interval 1340 to $1640 \mathrm{~nm}$. It is figured out the $x$-polarized mode to obtain optimum results like large negative dispersion, which overcome the limitations of [30] that contained a low dispersion coefficient (approximately $-1054.40 \mathrm{ps} /(\mathrm{nm} \cdot \mathrm{km}))$.

Figure 4 shows the effect of the air hole diameter $\left(d_{1}\right)$ located at 1 st layer on the dispersion behavior, when the other parameters $(\Lambda=0.80 \mu \mathrm{m}$, $d=0.76 \mu \mathrm{m}$, and $\left.d_{3}=0.55 \mu \mathrm{m}\right)$ are kept constant. According to the variations of $d_{1}$ and $\Lambda$ equal to $0.94,0.95$, and 0.96 , the evaluated dispersion coefficients at a wavelength of $1550 \mathrm{~nm}$ are $-1281.00,-1732.10$, and $-2663.00 \mathrm{ps} /(\mathrm{nm} \cdot \mathrm{km})$, re- 


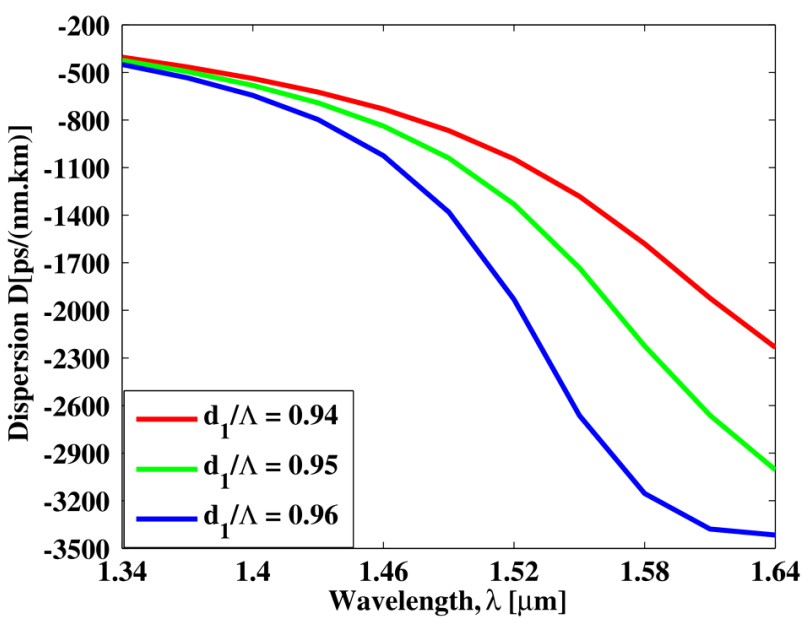

Fig. 4. Dispersion coefficient versus the wavelength for the proposed S-PCF for the optimum design parameters: $\Lambda=$ $=0.80 \mu \mathrm{m} ; d=0.76 \mu \mathrm{m} ; d_{1} / \Lambda=0.94,0.95,0.96$, and $d_{3}=0.55 \mu \mathrm{m}$

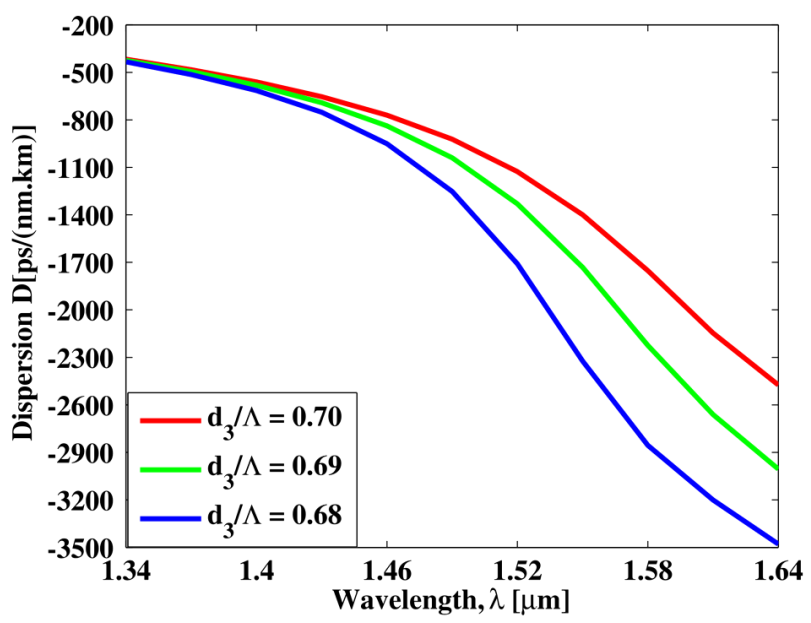

Fig. 5. Dispersion coefficient versus the wavelength for the proposed S-PCF for the optimum design parameters: $\Lambda=$ $=0.80 \mu \mathrm{m} ; d=0.76 \mu \mathrm{m} ; d_{3} / \Lambda=0.70,0.69$, and 0.68

spectively. From the above investigation, it is determined that the dispersion coefficient negatively promotes by increasing the value of $d_{1} \Lambda$. Due to this, the optical field is strongly confined to the core region, which allows one to achieve a higher negative dispersion coefficient than (approximately $-790.12 \mathrm{ps} /(\mathrm{nm} \cdot \mathrm{km}))[38]$.

The dispersion coefficient versus the wavelength curve is illustrated in Fig. 5 according to the variation of $d_{3} \Lambda$ by keeping the other parameters $(\Lambda=$ $=0.80 \mu \mathrm{m} ; d=0.76 \mu \mathrm{m})$ to be constant. According

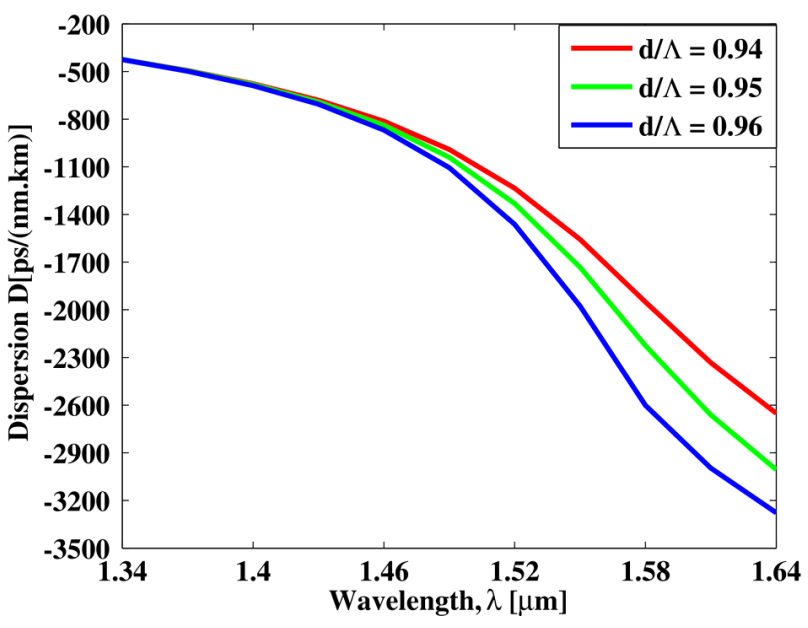

Fig. 6. Dispersion coefficient versus the wavelength for the proposed S-PCF for the optimum design parameters: $\Lambda=$ $=0.80 \mu \mathrm{m} ; d_{3}=0.55 \mu \mathrm{m} ; d / \Lambda=0.94,0.95$, and 0.96

to the variations of $\mathrm{d}_{3} / \Lambda$ as $0.70,0.69$, and 0.68 , the evaluated dispersion coefficients at a wavelength of $1550 \mathrm{~nm}$ are about $-2324.40,-1732.10$, and $-1400.60 \mathrm{ps} /(\mathrm{nm} \cdot \mathrm{km})$, respectively. The variation of $d_{3} \Lambda$ has a great effect on the dispersion coefficient demonstrated in Fig. 5. From the above investigation, it is determined that the dispersion coefficient negatively promotes by decreasing the air holes diameter $\mathrm{d}_{3}$. As a result, the optical field is strongly confined to the core region, which governs to achieve a highly negative dispersion than (approximately $-555.93 \mathrm{ps} /(\mathrm{nm} \cdot \mathrm{km})$ ) in [39].

Figure 6 exhibits the influence of $d$ on the dispersion coefficient. From this figure, it is clearly seen that the dispersion coefficient negatively enhances by increasing the value of $d / \Lambda$. At the operating wavelength $1550 \mathrm{~nm}$ for the variations of $d \Lambda$ as $0.94,0.95$, and 0.96 , the considered dispersion coefficients are $-1557.50,-1732.10$, and $-1977.00 \mathrm{ps} /(\mathrm{nm} \cdot \mathrm{km})$, respectively. There is an advantage of the high negative dispersion, specifically in optical amplification applications. Typical long traditional optical fiber links do not control the linear polarization; the Raman gain defines an average value, which is to be about half the corresponding polarized gain. Thus, by maintaining the linear polarization, the gain efficiency may be developed by approximately a factor of 2 [40]. The proposed PCF is such that it exhibits a large negative dispersion, which governs to a rela-

ISSN 2071-0194. Ukr. J. Phys. 2017. Vol. 62, No. 9 


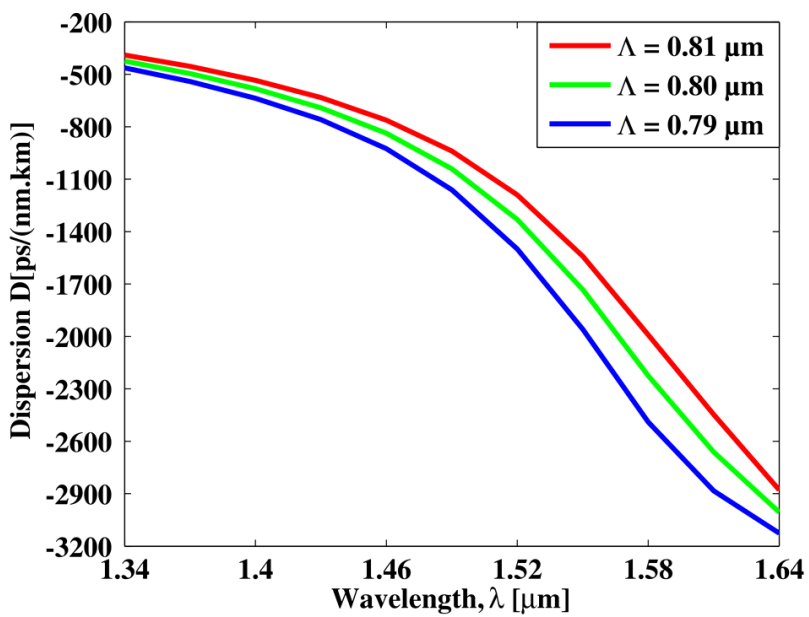

Fig. 7. Dispersion coefficient versus the wavelength for the proposed S-PCF for the optimum design parameters: $\Lambda=0.79$ 0.80 , and $0.81 \mu \mathrm{m} ; d_{3}=0.55 \mu \mathrm{m} ; d=0.76 \mu \mathrm{m}$

tively small fiber length required to acquire the dispersion compensation.

In Fig. 7, we represent the effect of a pitch $(\Lambda)$ variation on the dispersion behavior when the other parameters $d=0.76 \mu \mathrm{m}, d_{3}=0.55 \mu \mathrm{m}$ are kept constant. Now, the pitch $(\Lambda)$ variations are considered as $0.79,0.80$, and $0.81 \mu \mathrm{m}$. The calculated dispersion coefficients at $1550 \mathrm{~nm}$ are $-1960.20,-1732.10$, and $-1541.00 \mathrm{ps} /(\mathrm{nm} \cdot \mathrm{km})$, respectively. From the above investigations, it is clear that the large negative dispersion can be obtained by alleviating a pitch for broadband dispersion compensation. It is also regarded that our proposed PCF can compensate the dispersion coefficient about 3 times more than in [41], which is compatible in the optical communication.

The single-mode operation of the proposed PCF can be determined using $V$ effective $\left(V_{\text {eff }}\right)$ parameter. Figure 8 illustrates the $V_{\text {eff }}$ parameter as a function of the wavelength with optimized design parameters, namely, $\Lambda=0.80 \mu \mathrm{m}, d=0.76 \mu \mathrm{m}$, and $d_{3}=0.55 \mu \mathrm{m}$. The $V_{\text {eff }}$ parameter can be obtained from expression (5). With an approximate perfect electric and magnetic conductor boundary condition, we used FEM at the outer enclosure to obtain the index of space-filling mode [42]. $V_{\text {eff }}$ parameter for a single-mode fiber (SMF) is $V_{\text {eff }} \leq 2.405$ formulated in [30]. From Fig. 8, it can be noticed that the gained $V_{\text {eff }}$ value is about 1.30 at the wavelength $1550 \mathrm{~nm}$, which is less than 2.405. According to the simulation,

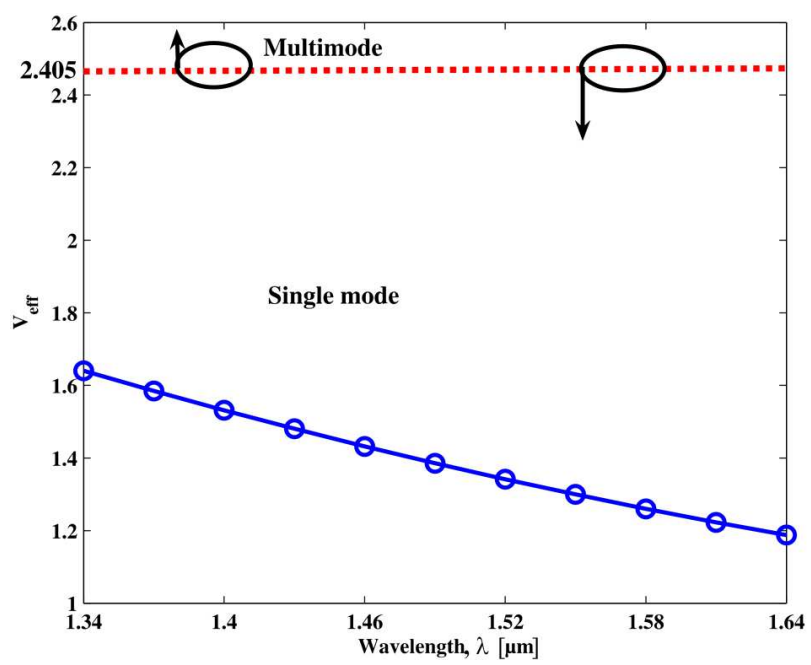

Fig. 8. $V$ parameter of the proposed S-PCF as a function of the wavelength for $\Lambda=0.80 \mu \mathrm{m}, d=0.76 \mu \mathrm{m}$, and $d_{3}=$ $=0.55 \mu \mathrm{m}$

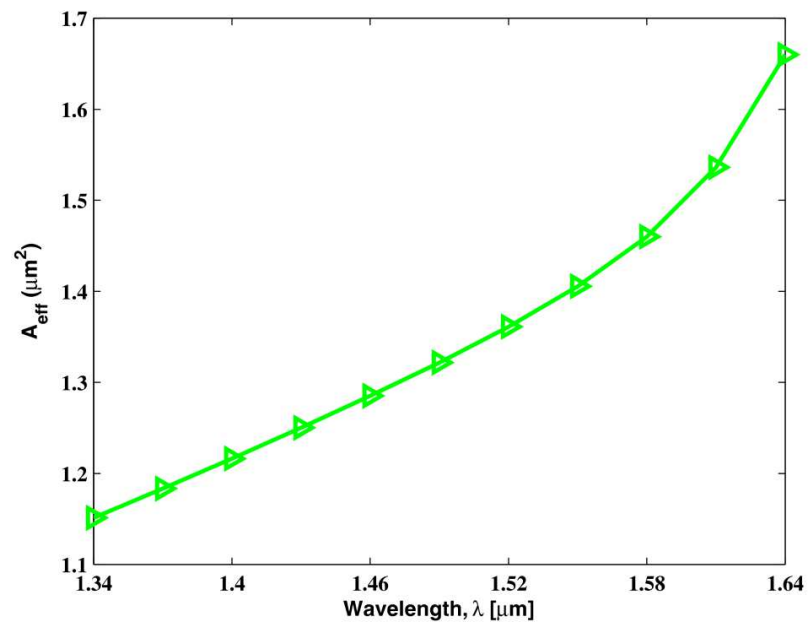

Fig. 9. Effective area for the $x$-polarization mode of the proposed PCF as a function of the wavelength for $\Lambda=0.80 \mu \mathrm{m}$, $d=0.76 \mu \mathrm{m}$, and $d_{3}=0.55 \mu \mathrm{m}$

it is clearly reported that the proposed PCF acts as an SMF over the whole bands. So the proposed SPCF will be highly applicable in long-distance optical communications.

Figure 9 illustrates the effective mode area of the proposed PCF as a function of the wavelength for the optimized parameters, $\Lambda=0.80 \mu \mathrm{m}, d=0.76 \mu \mathrm{m}$, and $d_{3}=0.55 \mu \mathrm{m}$. The figure also shows that the effective area increases with the wavelength. The mode power is closely absorbed in the core region at 


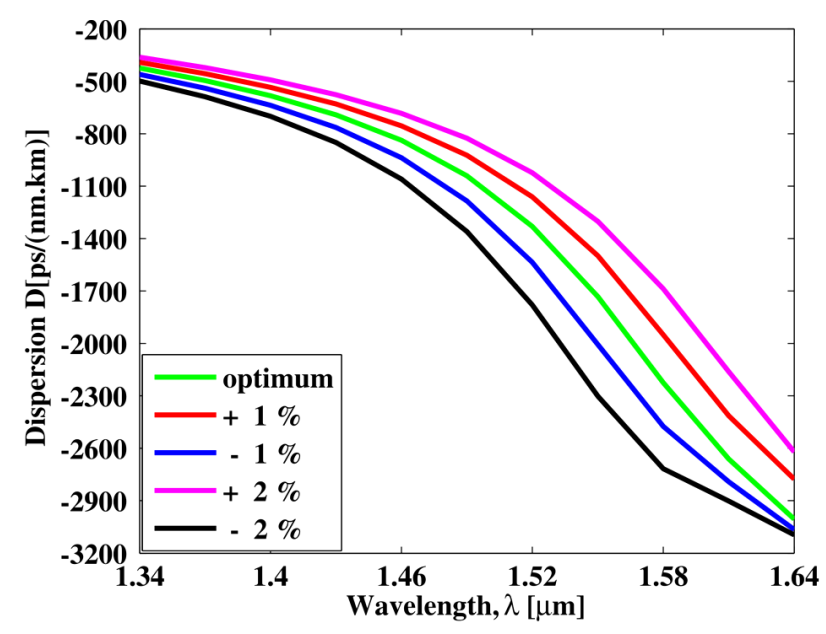

Fig. 10. Dispersion versus the wavelength curve of the S-PCF: optimum design parameters and variations of fiber's global parameters of order $\pm 1 \%$ and $\pm 2 \%$ around the optimum value

the longer wavelength, so the guiding waves diverse largely. The effective area of our offered structure is found about $1.40 \mu \mathrm{m}^{2}$ at $1550 \mathrm{~nm}$. Our proposed PCF is desired to be hard to be bent due to the small effective area [43]. It is also regarded that the small effective mode area has a crucial effect on bending loss [37].

The dispersion coefficient of $-1732.10 \mathrm{ps} /(\mathrm{nm} \cdot \mathrm{km})$ at an operating wavelength of $1550 \mathrm{~nm}$, which is definitely higher than [39]. After plotting the dispersion curve to the desired level (Fig. 3), it has been observed the dispersion validity of the proposed design PCF. During the fabrication, $\pm 1 \%$ variations of global parameters may occur in a standard fiber draw [29]. To ensure the dispersion tolerance, an accuracy of $\pm 2 \%$ may be required. In our proposed $\mathrm{PCF}$, the global parameters are varied up to $2 \%$

Comparison between properties of the proposed PCF and prior PCFs at $1550 \mathrm{~nm}$ wavelength

\begin{tabular}{|c|c|c|}
\hline Ref. & $D, \mathrm{ps} /(\mathrm{nm} \cdot \mathrm{km})$ & $A_{\text {eff }}, \mu \mathrm{m}^{2}$ \\
\hline$[29]$ & -588.00 & 3.43 \\
{$[30]$} & -1054.40 & - \\
{$[31]$} & -837.80 & 2.275 \\
{$[38]$} & -790.12 & 1.64 \\
{$[41]$} & -578.50 & 1.92 \\
Proposed PCF & -1723.10 & 1.40 \\
\hline
\end{tabular}

to gain a better dispersion accuracy. Figure 10 exhibits the corresponding dispersion curve with variations of global parameters $\pm 1 \%$ and $\pm 2 \%$. At the wavelength $1550 \mathrm{~nm}$, the dispersion coefficient can be gained $-1498.30,-1301.80 \mathrm{ps} /(\mathrm{nm} \cdot \mathrm{km})$ and $-2006.90,-2301.60 \mathrm{ps} /(\mathrm{nm} \cdot \mathrm{km})$ by increasing and decreasing the global parameters order of $1 \%$ and $2 \%$, respectively. In addition, it is evident that the dispersion curve provides a negative dispersion, which is a precondition for the wide-band dispersion compensation of a traditional single mode fiber.

A comparison among characteristics of the proposed PCF and some other conventional designs for dispersion compensation applications is shown. Table illustrates the comparison with account for the dispersion $(D)$ and the effective area $\left(A_{\text {eff }}\right)$. From Table, it is clearly visualized that our proposed PCF offers the superior result for the dispersion coefficient than prior PCFs. Our proposed PCF gains about $2.94,1.64,2.07,2.19$, and 3 times higher negative dispersion than in $[29,30,31,38,41]$, respectively. So, this demonstrates definitelythat the proposed PCF is better for the dispersion compensation than prior PCFs. Our proposed PCF also exhibits the simplicity in design compare with prior PCFs [30, 39]. Hence, the fundamental tasks like the fabrication process become comparatively easier.

With this context, the fabrication flexibility of the proposed structure has been investigated. In Fig. 1, we represent that it forms a square lattice in the cladding, which offers an additional efficiency during the fabrication. The conventional stack and draw technique is perfect for the fabrication of the PCF, because this method gives a good degree of exactness for the closed packed geometry like a triangular or honeycomb lattice [38]. Another technique, the drilling method offers the adjustment of both size and spacing of holes, as well as it can procreate circular shapes perfectly. However, by the currently advanced technology, the proposed structure can ensure the technological advancement in the fabrication of PCFs. The sol-gel technique provided by Bise et al. [44] is used to fabricate the PCFs with all structures, and they also offer the freedom to adjust the air-hole size, shape, and spacing. Additionally, the sol-gel casting method allows the design flexibility, which will be perfect for the proposed PCF. So, our proposed $\mathrm{S}-\mathrm{PCF}$ can easily be fabricated by the sol-gel casting method.

ISSN 2071-0194. Ukr. J. Phys. 2017. Vol. 62, No. 9 


\section{Conclusions}

In conclusion, a single-mode wideband dispersion compensating fiber including the large negative dispersion coefficient has been offered and is based on the square-lattice geometry of PCFs. The numerical investigations represent that the proposed design offers a highly negative dispersion coefficient ranging from about -424.40 to $-3000.60 \mathrm{ps} /(\mathrm{nm} \cdot \mathrm{km})$ over the operating wavelengths from 1340 to $1640 \mathrm{~nm}$. From above simulations, it can be reported on that the dispersion property does not vary much even, if there are several variations of the design parameters. Due to the luscious index-guiding behavior, the proposed design will be compatible for the broadband dispersion compensation in high-speed transmission systems, as well as for sensing applications.

There was no funding for this research. The authors are grateful to those, who participated in this research work.

1. J.A. Buck. Fundamentals of Optical Fibers (Wiley, 2004).

2. S. V. Kartalopoulos. DWDM Networks. Devices, and Technology (Wiley, 2003).

3. S. Soussi. Modeling photonic crystal fibers. Adv. in Applied Math. 36, 288 (2006).

4. C.J. Knight. Photonic crystal fibres. Nature 424, 847 (2003).

5. J. Hecht. Understanding fiber optics (Laser Light Press, 2015) [ISBN: 9781511445658].

6. J. Broeng et al. Photonic crystal fibers: A new class of optical waveguides. Optical Fiber Techn. 5, 305 (1999).

7. Ph. Russell. Photonic crystal fibers. Science 299, 358 (2003).

8. S. Asaduzzaman, K. Ahmed. Proposal of a gas sensor with high sensitivity, birefringence and nonlinearity for air pollution monitoring. Sensing and Bio-Sensing Research 10, 20 (2016).

9. Z. Yang et al. Research on leakage detection and analysis of leakage point in the gas pipeline system. Open J. of Safety Science and Technology 01, 94 (2011).

10. J.P. Carvalho et al. Remote system for detection of lowlevels of methane based on photonic crystal fibres and wavelength modulation spectroscopy. J. Sensors 2009, 1 (2009).

11. G.F. Fine et al. Metal oxide semiconductor gas sensors in environmental monitoring. Sensors 10, 5469 (2010).

12. H. Xuan et al. Polarization converters in highly birefringent microfibers. Opt. Express 22, 3648 (2014).

13. E.K. Akowuah et al. Numerical analysis of a photonic crystal fiber for biosensing applications. IEEE J. Quantum Electronics 48, 1403 (2012).

ISSN 2071-0194. Ukr. J. Phys. 2017. Vol. 62, No. 9
14. S. Olyaee et al. High sensitivity evanescent-field gas sensor based on modified photonic crystal fiber for gas condensate and air pollution monitoring. Optik - Int. J. for Light and Electron Optics 125, 596 (2014).

15. D. Wu et al. Experimental research on FLM temperature sensor with an ethanol-filled photonic crystal fiber. Sensors and Actuators A: Phys. 209, 62 (2014).

16. M. Rabiul Hasan et al. Polarization-maintaining low-loss porous-core spiral photonc crystal fiber for terahertz wave guidance. Appl. Opt. 55, 4145 (2016).

17. H. Ademgil, S. Haxha. Endlessly single mode photonic crystal fiber with improved effective mode area. Opt. Commun. 285, 1514 (2012).

18. P. Petropoulus et al. 2R-regenerative all-optical switch based on a highly nonlinear holey fiber. Opt. Lett. 26, 1233 (2001).

19. R. Bhattacharya, S. Konar. Extremely large birefringence and shifting of zero dispersion wavelength of photonic crystal fibers. Optics and Laser Techn. 44, 2210 (2012).

20. Y. Liu et al. A novel hybrid photonic crystal dispersion compensating fiber with multiple windows. Optics and Laser Techn. 44, 2076 (2012).

21. P.S. Maji, P. Roy Chaudhuri. Designing an ultra-negative dispersion photonic crystal fiber with square-lattice geometry. ISRN Opt. 2014 (2014).

22. B. Zsigri et al. A novel photonic crystal fibre design for dispersion compensation. J. Optics A: Pure Appl. Opt.6, 717 (2004).

23. F. Gérôme et al. Design of dispersion-compensating fibers based on a dual-concentric-core photonic crystal fiber. Opt. Lett. 29, 2725 (2004).

24. S. Yang et al. Theoretical study and experimental fabrication of high negative dispersion photonic crystal fiber with large area mode field. Opt. Exper. 14, 3015 (2006).

25. F. Poli et al. Single mode regime of square-lattice photonic crystal fibers. J. Opt. Soc. Am. A: Opt. Image Sci. Vision. 22, 1655 (2005).

26. T.A. Birks et al. Dispersion compensation using singlematerial fibers. IEEE Photon. Technol. Lett. 11, 674 (1999).

27. L.P. Shen et al. Design and optimization of microstructure fibers for broad-band dispersion compensation. IEEE Photon. Technol. Lett. 15, 540 (2003).

28. M. Samiul Habib et al. Relative dispersion slope matched dispersion compensating highly birefringent spiral microstructure optical fibers using defected core. Opt. Engin. 52, 096110, (2013).

29. M. Selim Habib et al. Proposal for highly birefringent broadband dispersion compensating octagonal photonic crystal fiber. Opt. Fiber Technol. 19, 461 (2013).

30. M.I. Hasan et al. Design of hybrid photonic crystal fiber: Polarization and dispersion properties. Photonics and Nanostructures - Fundamentals and Applications 12, 205 (2014). 
31. A. Halder, S.A. Hossain. Design of ultra-high birefringent broadband dispersion compensating photonic crystal fiber for high speed transmission system. Imperial J. of Interdisc. Res. 2, 211 (2016).

32. H. Ademgil et al. Highly nonlinear bending insensitive birefringent photonic crystal fibres. Engineering 2, 608 (2010).

33. S. Yang et al. Broadband dispersion-compensating photonic crystal fiber. Opt. Lett. 31, 2830 (2006).

34. M.K. Lee et al. Negative refraction experiments with guided shear-horizontal waves in thin phononic crystal plates. Appl. Phys. Lett. 98, 011909 (2011).

35. P.S. Maji, P. Roy Chaudhuri. Dispersion properties of the square-lattice elliptical-core PCFs. Am. J. Opt. Photonics 2, 1 (2014).

36. K. Saitoh, M. Koshiba. Full-vectorial imaginary-distance beam propagation method based on a finite element scheme: Application to photonic crystal fibers. IEEE J. Quantum Electron. 38, 927 (2002).

37. S.F. Kaijage et al. Broadband dispersion compensating octagonal photonic crystal fiber for optical communication applications. Japan. J. of Appl. Phys. 48052401 (2009).

38. M.M. Haque et al. Design and characterization of single mode circular photonic crystal fiber for broadband dispersion compensation. Optik - Int. J. for Light and Electron Optics 125, 2608 (2014).

39. M.I. Hasan et al. Highly nonlinear and highly birefringent dispersion compensating photonic crystal fiber. Optical Fiber Techn. 20, 32 (2014).

40. R.H. Stolen. Polarization effects in fiber Raman and Brillouin lasers. IEEE J. Quantum Electron. 15, 1157 (1979).

41. Md Rabiul Hasan et al. A single-mode highly birefringent dispersion-compensating photonic crystal fiber using hybrid cladding. J. Modern Opt. 64, 218 (2017).

42. M. Selim Habib et al. Microstructure holey fibers as wideband dispersion compensating media for high speed transmission system. Optik - Int. J. for Light and Electron Optics 124, 4984 (2013).
43. Q. Li. et al. Research on dispersion compensating property and nonlinear coefficient of photonic crystal fiber. Photonics and Optoelectronics. SOPO 2009. Symposium of IEEE. 1 (2009).

44. H. El Hamzaoui et al. Sol-gel derived ionic copper-doped microstructured optical fiber: A potential selective ultraviolet radiation dosimeter. Opt. Express 20, 29751 (2012).

Received 15.03.17

М.І. Іслам, М. Хатун, К. Ахмед,

С. Асадуззаман, Б.К. Паул, М.С. Іслам,

C. Чоудxypi, C. Сіна, М.Б.А. Miaxa, А.Н. Бахар

РОЗРОБКА ТА АНАЛІЗ ОДНОМОДОВОГО

НИТКОПОДІБНОГО ФОТОННОГО КРИСТАЛА

ДЛЯ ОПТИЧНОГО ЗВ'ЯЗКУ ВІД Е ДО L СМУГАХ

З УЛЬТРАВИСОКОЮ НЕГАТИВНОЮ ДИСПЕРСІЄЮ

$\mathrm{P}$ е $з$ ю м е

Представлено одномодовий квадратного перетину ниткоподібний фотонний кристал $(\mathrm{O}-\mathrm{HФК)} 3$ широкосмуговою компенсацією дисперсії на довжинах хвиль від 1340 до 1640 нм у вікні телекомунікаціі. У всій смузі частот застосований метод кінцевих елементів для чисельного аналізу деяких основних властивостей НФК. Пропонований НФК строго одномодовий, має дуже високий негативний коефіцієнт дисперсії близько -1732,10 пс/(нм · км) на робочій довжині хвилі 1550 нм і добре застосовується в оптичних передавальних системах. В дослідженні О-НФК використаний $V$ параметр. Ретельний дисперсійний аналіз показав, що цей НФК надійніший при отриманні високого негативного коефіцієнта дисперсї і більш різнобічний порівняно 3 відомими раніше. У швидких передавальних системах такі НФК ефективні завдяки компенсації дисперсії і збереженню однієї поляризації. Вони можуть бути застосовані в ниткоподібних петльових дзеркалах, при 4-хвильовому змішуванні і в інших випадках. 